\title{
1976 年唐山地震前地面增温异常*
}

\author{
徐秀登
}

(新江师范大学地理系, 金华 321004)

\section{货常 恭}

（国家气象局卫显年象中心，北京 100081）

\author{
臀祖 基
}

（国家地震局地质研究所，北京 100029）

$$
\text { 王 戈平 }
$$

（国家地震局地质研究所，北京 100029）

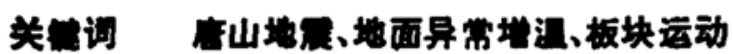

地震是一种急剧的构造运动、快速释放应变能的结果。热是各种形式运动和能量的集中 表现. 通过对 1989 年以来发生在我国的 20 多次 5 级以上地震的地面温度和卫星热红外图象 资料综合分析, 表明在短临时段内(震前几天至 20 多天), 震区及其外围出现区域性热红外异 常, 即地表产生大面积增温, 是一种普遍现象; 初步认为由于地壳运动加剧, 地球放出大量气体 和其它物质与能量,导致局部地表一低空大气增温所致; 故认定震前地面增温是地下瞬时地壳 运动的地表显示; 多是一种地震短临前兆信息 ${ }^{[-3]}$. 按照这个思路, 本文研究了 1976 年 7 月 28 日唐山 7.8 级强震前的地面增温异常及其时空演变规律, 不仅进一步证实了原有的上述认 识,并揭示了唐山强霞与我国相邻两大板块运动的关系.

\section{一、店山諼前大面积地面增温}

作者搜集了唐山震前(1976 年 6-7 月)我国 185 个气象台站凌晨 2 时 $0 \mathrm{~m}$ 的地面温度,作 温度一时间变化曲线,发现震区及其外围 135 个台站震前皆呈现趋势性增温. 增温起始时间先 后不一(表 1 (a)), 最早 7 月 2 日,最晚 23 日, 大多是 3 日和 4 日, 即趋势增温时间震前 5一 25 天不等. 累积增温幅度 (发展日温度值与增温起始日温度值之差) 最高 $1^{\circ} \mathrm{C}$, 大多 $6^{\circ} \mathrm{C}-$ ${ }^{9} \mathrm{C}$. 以累积增温幅度为基础, 参考趋势性明显程度, 将 185 个台站的 $T-t$ 曲线分为强、中、 弱、无异常四类 (表 1(b)). 可分别以唐山、北京、南昌和贑州为代表 (图 1); 图中一并绘出了 1966-1975 年 6-7 月逐日地面平均温度及 1975 年 7 月的地面温度曲线进行对比.

增温异常范围地区及各地增温起始时间的空间分布如图 2 .

对比分析上述资料可得到如下认识:

1. 异常区 7 月温度曲线与无霞的正常时期相比, 具较明显的趋势增温形态, 且增温峰值与 发震时间具较好对应性. 图 1 可见，1975 年 7 月和 1976 年 6 月 15 日- 7 月 3 日时段的温度 曲线基本呈无规则脉动状态, 无增温趋势性变化, 系代表正常的气象温度波动包含个别时间的 突跳. 1966-1975年的震前 10 年 7 月的逐日平均地面温度,代表了所在地区 7 月的一般气象 温度变化规律, 可作为衡量 1976 年 7 月是否异常及其强度的“尺子”. 该 “尺子”在我国西部 (以拉萨为例)是近乎水平的; 东部北方 (以唐山为例) 和南方 (以南昌为例) 有一定增温趋势, 但 比 1976 年 7 月 3 日始的趋势增温要平缓得多 (在唐山两者差约 $7^{\circ} \mathrm{C}$ ). 通过上述对比说明: 唐 山震前的 7 月初开始的趋势性增温, 并非是季节引起的单纯的气象增温, 而是在正常气象变化 的背景之上,叠加了孕震性地壳活动引起的增温异常.

1991-08-29 收稿,1992-06-01 收位改稆

“国家“八五”科技重点攻关项目 


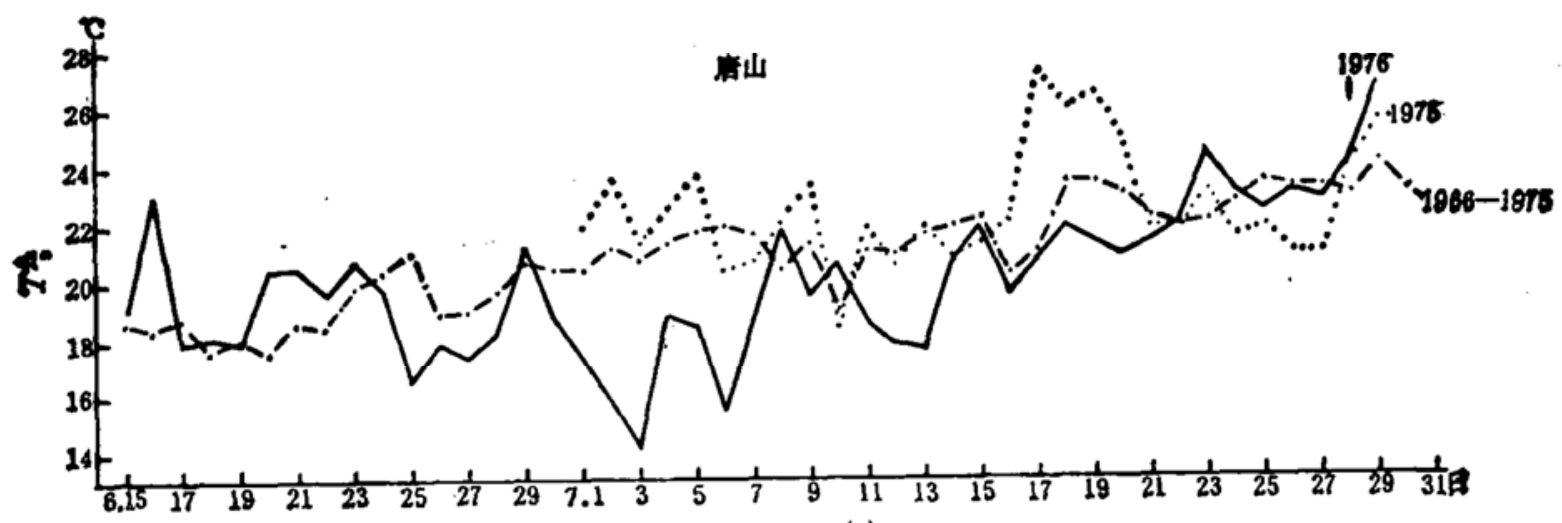

(a)

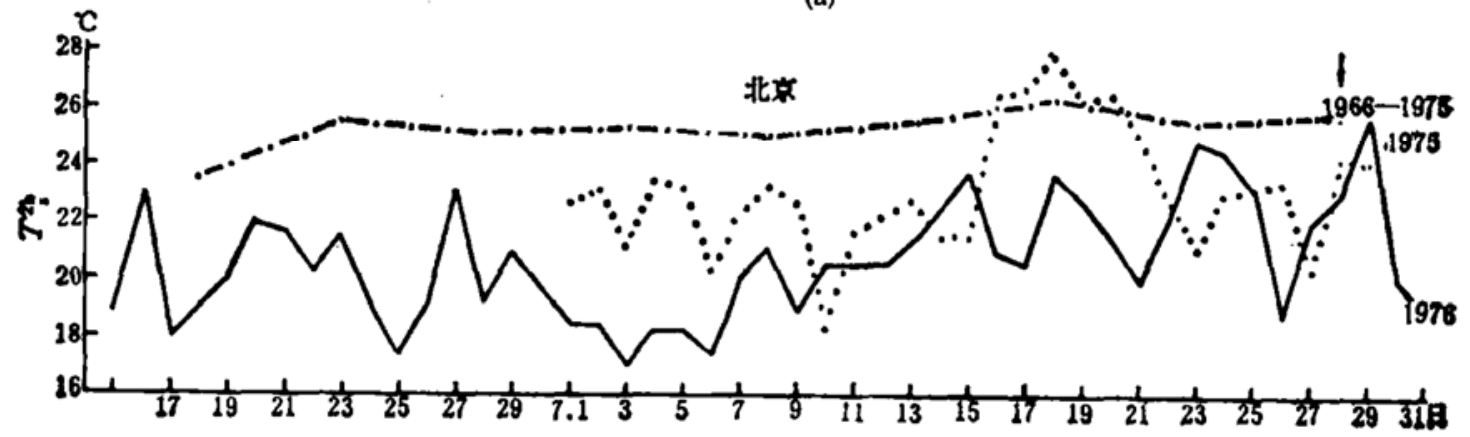

(b)
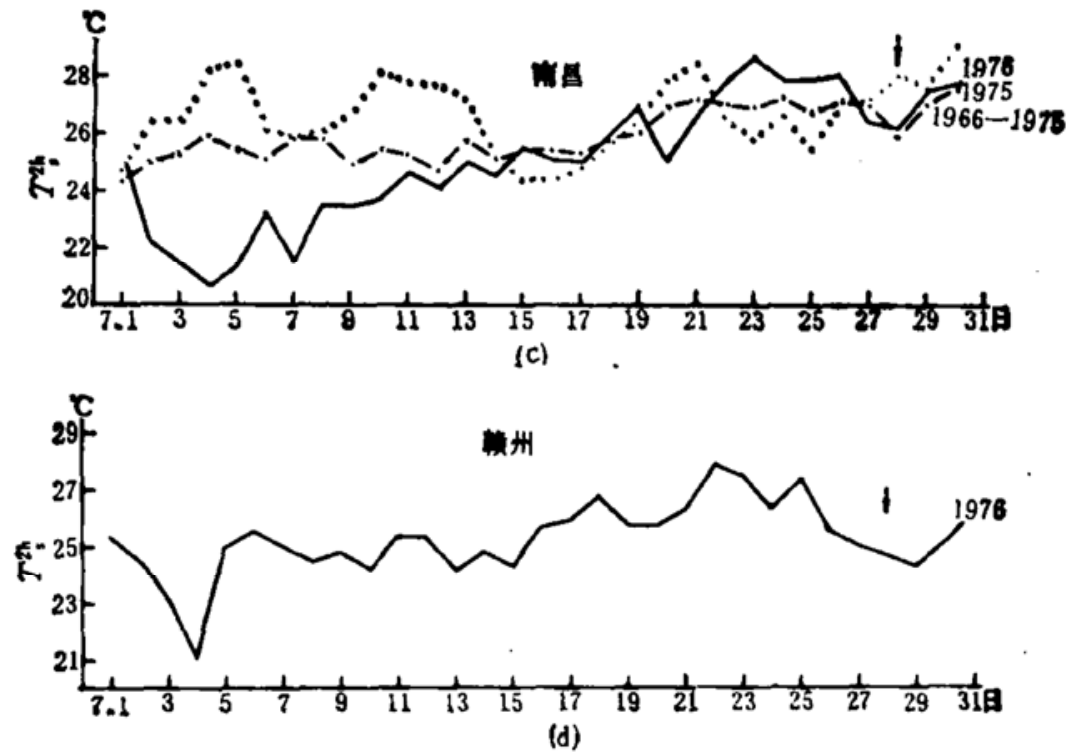

图 1 各类增温异常曲线对比图

（s）强异常，(b) 中异常，(c) 羽开常，(d) 无异常

2. 趋势性增温异常范围虽是大面积的, 但明显与大地构造位置有关并受活动构造控制, 而 与纬度、地形密切相关的气象温度分布不同. 异常区东北边界, 将东北平原拦腰截断. 异常区 两界, 从齐齐哈尔南面的白城开始, 沿 NNE 向大兴安岭东缘断裂南下, 到承德受纬向构造带 晌突然转向西行,到大同附近后折向 SSW, 异常区界冲破太行山脉,基本顺汾渭地暂行进, 后沿杼尔多斯块体西缘断裂南段折向 NNW. 东南面, 增温异常并未浸漫整个华南, 而是受 NE 向郡武一河源断裂和灵山断裂控制, 其间唼州一柳州段受南岭纬向带阻隔呈 $\mathrm{EW}$ 向, 致 使 7 月㢳温度较高的东南沿海诸省区, 反成了无增温异常的正常区. 西南面, 异常仅波及吡 
表 1 唐山倞前地面 0m、2 时增温情况统计表

(a)

\begin{tabular}{|l|r|}
\hline 增温起始日期 & 地点数 \\
\hline 7月2 日 & 8 \\
7 月3日 & 47 \\
7 月4日 & 24 \\
7 月5日 & 16 \\
7 月6-7日 & 4 \\
7 月8 日 & 8 \\
7 月9日 & 11 \\
7 月10-23日 & 17 \\
\hline
\end{tabular}

(b)

\begin{tabular}{|c|c|c|c|}
\hline 暑赏巽 & 具积境温 & 增温曲线形态 & 地点数 \\
\hline 虺异常 & $9.1-12$ & 趋势增温明显 & 22 \\
\hline 中开常 & $9-6$ & 趋势增温较明显 & 80 \\
\hline 果开常 & $5.9-3.5$ & 动动或间歌性, 趋势增温不太明显 & 33 \\
\hline 无异常 & $<3.5$ & 不规则波动无趋势增温 & 30 \\
\hline
\end{tabular}

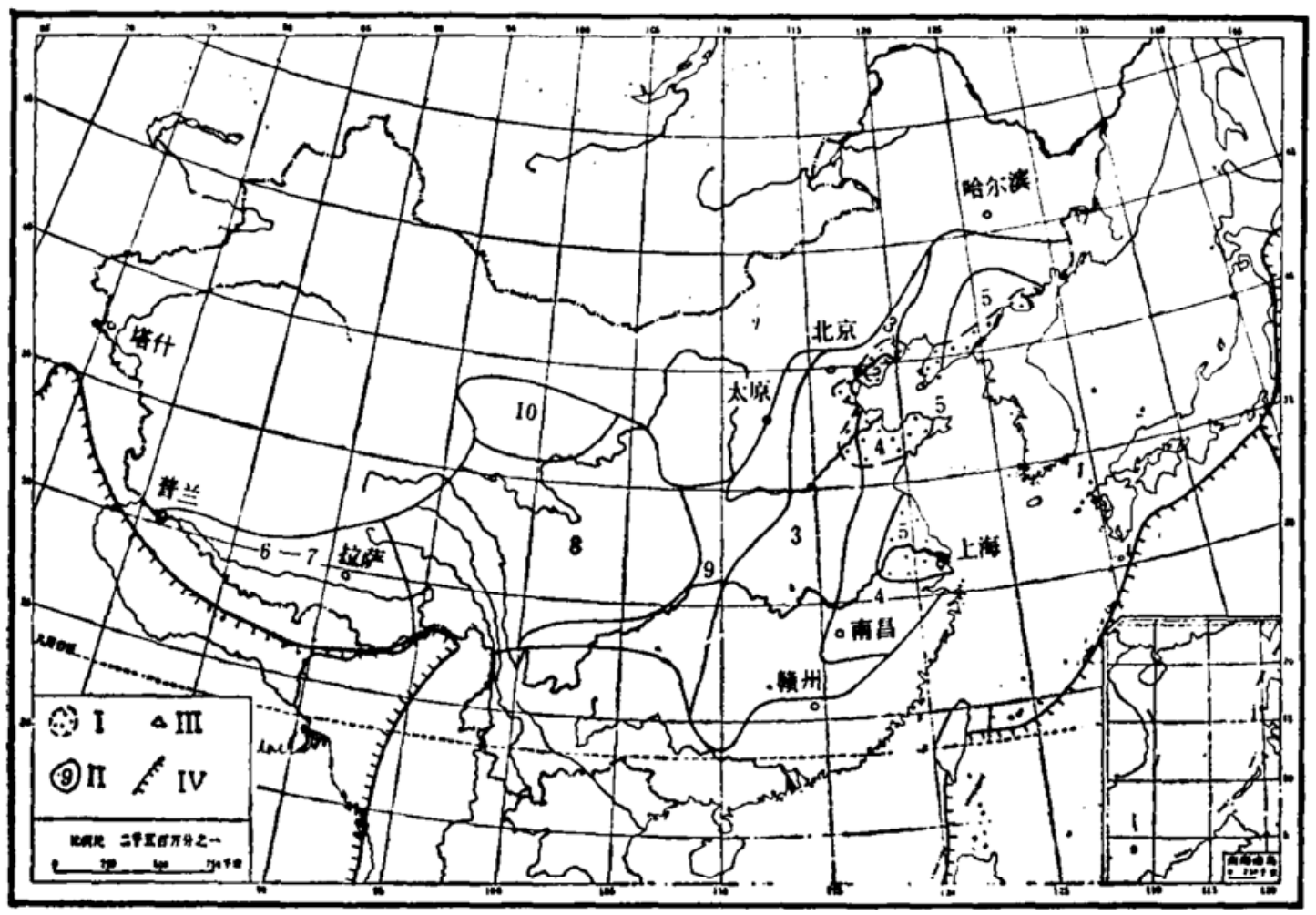

图 2 增温异常时空分布图

I. 强异常区, II. 䇎温起始日期, III. 震中位置, IV. 板块边界.

图中 $2,4,6,7,8,9,10$ 为起始日期

邻印度板块东北角的青藏断块东部; 异常西北界受祁连山北缘断裂围限; 受制于 NWW 向活 动断裂, 青海湖以西伸出了一个犄角. 上述异常分布范围说明, 它与正常气象背景关系不大, 而与地下活动构造紧密相关.

根据上述和其他地震震前的普遍增温现象, 可认为唐山震前 5 至 20 多天的趋势性增温是 地震临近时地应力加强构造活动加剧的显示, 是一种短临地震前兆信息.

\section{二、店山地面增盟异常时空分布与板块运动}

各地的增温强度和增温起始时间虽然不同，但在空间的分布并非杂乱无序而具有一定的 
规律性. 唐山震前地面增温异常的时空分布规律, 揭示了华北构造应力场与印度板块和太平 洋板块的关系及菑山地震的发生和两大板块运动的有机联系。

从异常分布范围看, 从东北一华北一华南的西部呈 NNE 向出现近 150 万 $\mathrm{km}^{2}$ 增温异 常; 西南部从青藏一川滇近 $\mathrm{EW}$ 西出现 200 多万 $\mathrm{km}^{2}$ 的大面积增温, 且两者互相贯通. 说明 中国构造应力场确是受太平洋板块和印度板块的联合作用控制的 ${ }^{(4)}$. 东南沿海一带无增温异 常,表明此时期菲律宾板块对我国影响不大.

从异常强度的空间展布看,除中间强、边缘弱的一般规律外, 总体上,东强西弱, 最强区在 色括震中在内的渤海周围和黄海海滨的江苏. 说明此时我国受太平洋板块 SWW 向挤压作 用为主, 尤以首当其冲的渤海周围和黄海海滨为最. 青藏断块区增温从西到东呈从无到有, 从 羽到强之势, 可用该断块受印度板块北移而引起向东滑动过程中, 受东面源自太平洋板块的呈 $s W W$ 向阻力加以解释;也可能此时期印度板块东北角活动较强之故.

增温起始时间的空间展布中,最引入注目的特征是 7 月 3 日和 9 日起始增温区的分界线, 即以齐齐哈尔以南的白城沿大兴安岭东麓, 越燕山, 经太行山, 穿秦岭, 顺云贵高原东鹿到贵州 东面的榕江附近的界线，竟与我国东部的第 3 条重力梯度带东界不谋而合. 整个异常范围就 以这条线为界,分作东西两大区,东区增温早, 7 月 2-5 日;西区晚, 7 月 6-10日或更晚.

东区: 以霞中区唐山以东的绥中、秦皇岛、乐亭等“前沿”地区和夹于两条活动断裂之间的 安徽鼻阳、六安和湖南的长沙、衡阳几处敏感点增温最早, 7 月 2 日就开始异常; 3 日向霞中推 进并向周围大面积扩大;而后 4 日、 5 日逐步向东扩展. 这种先向西后向东扩大的增温过程, 可以理解为 2-3 日, 相对稳定、整体性较强的东缘地壳,断裂尚未活动起来, 作为一个整体向 西推进, 随着应力的进一步加强, 4一-5日断裂开始活动, 周围产生微破裂, 放气增温.

西区: 北边增温起始最晚 ( 7 月 10 日), 因印度板块是由南向北推挤的; 其他地区,又以印 度板块前沿的西藏地方最早 ( $6-7$ 日). 往东逐渐变晚 ( $8 \rightarrow 9$ 日). 这表明印度板块呈 NNE 向推挤所产生的分力是从西向东传递的, 9 日传到了东区,使震中所在的华北断块区 9 日后在 受东部太平洋板块的 SWW 向挤压基础上,又受到源自印度板块北移的青藏断块的 NE 向挤 压,从而使东区许多地方 9 日后增温进一步加剧,和使某些地方间歇性增温.

由上可认为: 1976 年唐山 7.8 级强震是太平洋板块以 SWW 向和印度板块呈 NE-NNE 向相向夹击, 以太平洋板块为主的动力作用的产物. 因而增温面积很大。这使得唐山震前出 现微破裂以及令人不可思议的大范围宏观异常, 如大别山北麓和西安的地裂煡及其他宏观 现 象, 得以迎刃而解. 增温范围虽很大, 但根据强异常区和 7 月 2 日的最早增温地段向西推进 的方向, 可指示震中位置.

致谓本文得到国家地度局双起东研究员的指导和支持,在此深表感谢。

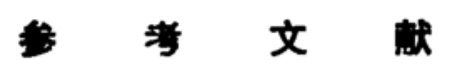

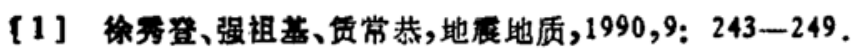

[2] 徐雪曋、强柤美、负常恭,科学通报,36(1991),4: 291-294.

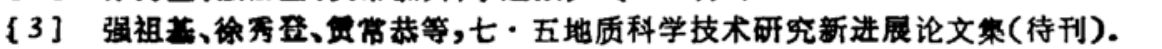

[4] 邓起东第,地层地质, 1979,1: 11-21.

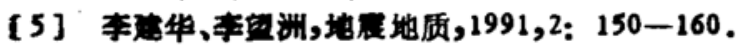

